\title{
Frequency of surgical complications and recurrence rate after extracapsular dissection of benign tumors of the parotid.
}

1. MBBS

Rawalpindi Medical University, Rawalpindi.

2. MBBS, FCPS, FRCS

Professor Surgery

Holy Family Hospital, Rawalpindi.

3. $4^{\text {th }}$ Year MBBS Student

Rawalpindi Medical University,

Rawalpindi.

4. MBBS, FCPS

Associate Surgery

Holy Family Hospital, Rawalpindi.

5. MBBS, FCPS

Associate Surgery

Holy Family Hospital, Rawalpindi.

6. MBBS, FCPS

Assistant Professor Surgery

Holy Family Hospital, Rawalpindi.

7. MBBS, FCPS

Senior Registrar Surgery

Holy Family Hospital, Rawalpindi.

8. MBBS, FCPS

Senior Registrar Surgery

Holy Family Hospital, Rawalpindi.

Correspondence Address:

Dr. Jahangir Sarwar Khan

House \#87, Bestridge 2, Rawalpindi. jskdr@hotmail.com

Article received on:

06/08/2020

Accepted for publication:

$11 / 11 / 2020$

\section{INTRODUCTION}

Salivary gland tumors constitute $3 \%$ to $10 \%$ of all cancers in the head and neck region. Parotid gland is the most commonly involved salivary gland and fortunately majority of the parotid growths have a benign histology. Of the benign parotid lesions, Pleomorphic adenoma and Warthin tumor are commonly encountered..$^{1-3}$ Surgery has been the mainstay of treating such tumors, however, the surgical technique has changed over the years.

Enucleation was the standard treatment before 1940s, in which the capsule was left in situ and the facial nerve was not dissected. Since pleomorphic adenoma has a poorly developed capsule, growth protrusions often extend into the surrounding normal tissue. Simple enucleation thus resulted in incomplete removal of the growth, leaving behind some tissue. Therefore, recurrence following enucleation was very frequent. This led to the introduction of a new technique known as superficial parotidectomy in which a large portion of the gland was removed. Although recurrence rates minimized, complications such as facial nerve dysfunction, Frey syndrome and disfigurement of the facial contour became a major concern. ${ }^{4}$

In search of a less invasive surgical procedure which would have the benefits of all previous techniques together with fewer complications, Anderson ${ }^{4}$ introduced extracapsular dissection of the parotid in 1975 which involves excision of the tumor with clear margins without dissecting the facial nerve. According to some recent studies ${ }^{5,6}$ extracapsular dissection has similar success rate in terms of recurrence as superficial parotidectomy, but fewer complications. On the contrary, some evidence suggests a higher rate of recurrence in patients undergoing extracapsular dissection as 
compared to superficial parotidectomy. ${ }^{7}$

Hence, it is still a matter of dispute that whether extracapsular dissection or superficial parotidectomy should be the preferred modality for the surgical management of benign tumors of the parotid. This led us to investigate the effectiveness and safety of extracapsular dissection in a tertiary health care unit of Pakistan.

\section{MATERIAL \& METHODS}

This retrospective study was conducted in the Department of Surgery, Rawalpindi Medical University, Rawalpindi. Ethical approval for this study was taken from Institutional Research Forum. Sample size calculated using WHO calculator was 50 .

50 patients who underwent extracapsular dissection between January 2010 and December 2018 with a diagnosis of either Pleomorphic adenoma or Warthin tumor were included in the study. Diagnosis of these benign tumors was established by ultrasound followed by FNAC. Any parotid swelling showing malignant histopathology was not included in the study group and hence was not treated by extracapsular dissection. Data regarding demographics (age and sex), tumor (size, site and relation to the facial nerve), complications (facial nerve injury, Frey syndrome, sialocele, salivary fistula, hematoma and rupture of capsule) and recurrence was collected. The mean duration of follow-up to assess post-operative complications and recurrence was 6 months. All the data was entered into SPSS version 23.

\section{Surgical Technique}

The operation was performed under general anesthesia with endotracheal intubation. A Lazy $S$ incision was used to raise the skin flap consisting of facial, mastoid and cervical parts. Facial nerve was identified in all cases of extra capsular dissection after confirming the important anatomical landmarks used for identification of facial nerve; including posterior belly of digastric and bony pointer. Facial nerve stimulation was not used. In order to prevent rupture of the tumor capsule, a wide dissection of the parenchyma surrounding the tumor was employed. A Redivac Drain was placed after tumor dissection. All cases were operated by a single surgeon.


Figure-1. a Patient with benign parotid tumor. b Curved incision around the earlobe. $c$ Tumor capsule being exposed. d Dissection extended through the healthy parenchyma surrounding the tumor.

\section{RESULTS}

A total of 50 patients underwent Extracapsular dissection. Out of 50 patients, 40 were males and 10 were females with age ranging from 26 to 52 years and mean age of 42 years. Table-I shows the pathological diagnosis of 50 parotid lesions. The range of lesion size was 1.5 to $3 \mathrm{~cm}$. In 43 cases the tumor was related to the upper trunk of the facial nerve and in 7 patients the lesion was located near the lower pole of the parotid gland. Table-Il shows the complications of extracapsular dissection. Recurrence was seen in only 1 patient $(2 \%)$ and required revision surgery.

\begin{tabular}{|c|c|}
\hline Type & No. (\%) \\
\hline Pleomorphic adenoma & $44(88)$ \\
\hline Warthin tumor & $06(12)$ \\
\hline \multicolumn{2}{|c|}{ Table-I. Histopathology of 50 parotid lesions. } \\
\hline Complication & No. (\%) \\
\hline Transient facial nerve weakness & $15(30)$ \\
\hline Facial nerve injury requiring repair & $1(2)$ \\
\hline Frey syndrome & 0 \\
\hline Salivary fistula & $1(2)$ \\
\hline Sialocele & 0 \\
\hline Hematoma & 0 \\
\hline Rupture of capsule & $15(30)$ \\
\hline \multicolumn{2}{|c|}{$\begin{array}{l}\text { Table-II. Complications of extracapsular dissection } \\
\qquad(n=50)\end{array}$} \\
\hline
\end{tabular}




\section{DISCUSSION}

Surgery is the mainstay of management for benign parotid growths. Attempts have been made in the past century to develop a technique for treating these lesions with the least possible complications and low rates of recurrence. ${ }^{4}$ Currently, extracapsular dissection and superficial parotidectomy are preferred over previous surgical procedures. ${ }^{5}$ Ozturk et al. ${ }^{5}$ have illustrated that both, extracapsular dissection and superficial parotidectomy, have similar results in terms of recurrence rate. Authors of a study conducted in Medical University of Vienna reported a higher recurrence rate $(7.3 \%)$ in patients undergoing extracapsular dissection as compared to superficial parotidectomy $(2.2 \%) .{ }^{7}$ Our results show a recurrence rate of $2 \%$, supporting the former claim. These differences could be explained by the fact that follow-up duration was not the same in all studies. Recurrence at long term follow-up can be attributed to capsule rupture during surgery. However, rate of capsule rupture was high $(30 \%)$ in our series without affecting the recurrence rate. Short follow-up in our study could be a possible explanation.

The results of this study demonstrate that extracapsular dissection is associated with reduced morbidity and lower risks of complications as supported by previous work of many authors. A meta-analysis by Xie et al. ${ }^{8}$ demonstrated reduced rates of permanent facial nerve weakness, transient CN VII injury and Frey syndrome in patients undergoing extracapsular dissection as compared to superficial parotidectomy. In our series only 1 patient (2\%) suffered from facial nerve injury which required repair.

Frey syndrome is a complication of parotid surgery which occurs due to aberrant regeneration of the secretomotor nerve fibers carried in the auriculotemporal nerve. Literature illustrates that the risk of Frey syndrome after superficial parotidectomy is more as compared to extracapsular dissection.9,10 Unlike extracapsular dissection, superficial parotidectomy exposes large raw surfaces of the gland to the subcutaneous layer, which could be a possible reason for this difference. Frey syndrome was not reported in any of our patients. Similarly, postoperative hematoma and sialocele were also not seen in our cases.

Since evidence points towards reduced complications after extracapsular dissection in addition to preservation of parotid salivary function and facial contour, many groups now consider superficial parotidectomy unnecessary for treating benign lesions of the parotid. However, extracapsular dissection is not recommended for malignant tumors of the parotid, making preoperative FNAC necessary to rule out malignancy before selecting the type of surgical intervention, as was done in our setting. ${ }^{11}$

Following the global trend of adopting minimally invasive surgical techniques, findings of our study illustrate that extracapsular dissection can replace superficial parotidectomy as a safe and effective treatment for benign parotid tumors in Pakistan, although further studies with longer follow-ups are recommended.

\section{CONCLUSION}

Extracapsular dissection of the parotid is associated with low recurrence rate, very few complications and is a safe and effective treatment for benign tumors of the parotid.

Copyright(C) 11 Nov, 2020.

\section{REFERENCES}

1. Correia-Sá IB, Correia-Sá M, Costa-Ferreira P, Silva Á, Marques $M$. Eleven years of parotid gland surgery in a plastic and reconstructive department. Journal of Craniofacial Surgery. 2016 Jan 1; 27(1):e26-33.

2. Stein AP, Britt CJ, Saha S, McCulloch TM, Wieland AM, Harari PM, Hartig GK. Patient and tumor characteristics predictive of primary parotid gland malignancy: A 20-year experience at the University of Wisconsin. American Journal of Otolaryngology. 2015 May 1; 36(3):429-34.

3. Zhan KY, Khaja SF, Flack AB, Day TA. Benign parotid tumors. Otolaryngol Clin North Am. 2016 Apr 1; 49(2):327-42. 
4. Foresta E, Torroni A, Di Nardo F, De Waure C, Poscia A, Gasparini G, Marianetti TM, Pelo S. Pleomorphic adenoma and benign parotid tumors: Extracapsular dissection vs superficial parotidectomy-review of literature and meta-analysis. Oral surgery, oral medicine, oral pathology and oral radiology. 2014 Jun $1 ; 117(6): 663-76$.

5. Ozturk K, Ozturk A, Turhal G, Kaya I, Akyildiz S, Uluoz U. Comparative outcomes of extracapsular dissection and superficial parotidectomy. Acta OtoLaryngologica. 2019 Dec 2; 139(12):1128-32.

6. Kato MG, Erkul E, Nguyen SA, Day TA, Hornig JD, Lentsch EJ, Gillespie MB. Extracapsular dissection vs superficial parotidectomy of benign parotid lesions: Surgical outcomes and cost-effectiveness analysis. JAMA Otolaryngology-Head \& Neck Surgery. 2017 Nov $1 ; 143(11): 1092-7$.

7. Kadletz L, Grasl S, Grasl MC, Perisanidis C, Erovic BM. Extracapsular dissection versus superficial parotidectomy in benign parotid gland tumors: The Vienna Medical School experience. Head \& neck. 2017 Feb; 39(2):356-60.
8. Xie S, Wang K, Xu H, Hua RX, Li TZ, Shan XF, Cai ZG. PRISMA-extracapsular dissection versus superficial parotidectomy in treatment of benign parotid tumors: Evidence from 3194 patients. Medicine. 2015 Aug; 94(34).

9. Lin YQ, Wang Y, Ou YM, Dong SY, Wang YD. Extracapsular dissection versus partial superficial parotidectomy for the treatment of benign parotid tumors. International journal of oral and maxillofacial surgery. 2019 Jul 1; 48(7):895-901.

10. Martin $H$, Jayasinghe $J$, Lowe $T$. Superficial parotidectomy versus extracapsular dissection: Literature review and search for a gold standard technique. International journal of oral and maxillofacial surgery. 2020 Feb 1; 49(2):192-9.

11. Mantsopoulos K, Mueller S, Goncalves M, Koch M, Iro $\mathrm{H}$. Completion surgery after extracapsular dissection of low $\square$ grade parotid gland malignant tumors. Head \& neck. 2019 Sep;41(9):3383-8.

\begin{tabular}{|c|l|l|}
\hline \multicolumn{2}{|c|}{ AUTHORSHIP AND CONTRIBUTION DECLARATION } \\
\hline Sr. \# & \multicolumn{1}{|c|}{ Author(s) Full Name } & \multicolumn{1}{|c|}{ Contribution to the paper } \\
\hline 1 & Muhammad Arham & 1st Author \\
\hline 2 & Jahangir Sarwar Khan & 2nd Author \\
\hline 3 & Muhammad Arish & 3rd Author \\
\hline 4 & Naveed Akhtar Malik & 4th Author \\
\hline 5 & Usman Qureshi & 5th Author \\
\hline 7 & Gohar Rasheed & Sth Author \\
\hline 8 & Sarosh Afzal Farooqi & 8th Author
\end{tabular}

